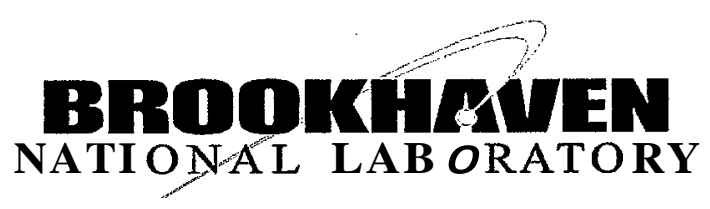

BNL-73497-2005-CP

\title{
Beam Induced Pressure Rise in RHIC
}

S.Y. Zhang, J. Alessi, M. Bai, M. Blaskiewicz, P. Cameron, A. Drees, W. Fischer, J. Gullotta, P. He, H.C. Hseuh, H. Huang, U. Iriso, R. Lee, V. Litvinenko, W.W. MacKay, A. Nicoletti, B. Oerter, S. Peggs, F. Pilat, V. Ptitsyn, T. Roser, T. Satogata, L. Smart, L. Snydstrup, P. Thieberger, D. Trbojevic,L. Wang, J. Wei, K. Zeno

\section{Presented at the Particle Accelerator Conference(PAC'05) Knoxville, Tennessee May 16-20, 2005}

\author{
Collider-Accelerator Department
}

\author{
Brookhaven National Laboratory \\ P.O. Box 5000 \\ Upton, NY 11973-5000 \\ www.bnl.gov
}

Managed by

Brookhaven Science Associates, LLC

for the United States Department of Energy under

Contract No. DE-AC02-98CH10886

This is a preprint of a paper intended for publicationin a journal or proceedings. Since changes may be made before publication, this preprint is made availablewith the understanding that it will not be cited or reproduced without the permission of the author. 


\section{DISCLAIMER}

This report was prepared as an account of work sponsored by an agency of the United States Government. Neither the United States Government nor any agency thereof, nor any of their employees, nor any of their contractors, subcontractors, or their employees, makes any warranty, express or implied, or assumes any legal liability or responsibility for the accuracy, completeness, or any third party's use or the results of such use of any information, apparatus, product, or process disclosed, or represents that its use would not infringe privately owned rights. Reference herein to any specific commercial product, process, or service by trade name, trademark, manufacturer, or otherwise, does not necessarily constitute or imply its endorsement, recommendation, or favoring by the United States Government or any agency thereof or its contractors or subcontractors. The views and opinions of authors expressed herein do not necessarily state or reflect those of the United States Government or any agency thereof:

FOR UNCLASSIFIED, UNLIMITED STI PRODUCTS

Available electronically at:

OSTI:

http://Www sosti.gov/bridge

Available for a processing fee to U.S. Department of Energy and its contractors, in paper from:

U.S. Department of Energy

Office of Scientific and Technical Information

P.O. Box 62

Oak Ridge, TN 37831

Phone: (865) 576-8401

Facsimile: (865) 576-5728

E-mail: reports@adonis.osti.gov

National Technical Information Service (NTIS):

Available for sale to the public from:

U.S. Department of Commerce

National Technical Information Service

5285 Port Royal Road

Springfield, VA 22131

Phone: (800) 553-6847

Facsimile: (703) 605-6900

Online ordering: http://www.ntis.gov/ordering.htm

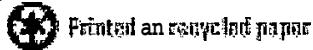




\title{
Beam Induced Pressure Rise in RHIC*
}

\author{
S.Y.Zhang, J. Alessi, M. Bai, M. Blaskiewicz, P. Cameron, A. Drees, W. Fischer, J. Gullotta, \\ P. He, H.C. Hseuh, H. Huang, U. Iriso, R. Lee, V. Litvinenko, W.W. MacKay, A. Nicoletti, \\ B. Oerter, S. Peggs, F. Pilat, V. Ptitsyn, T. Roser, T. Satogata, L. Smart, L. Snydstrup, \\ P. Thieberger, D. Trbojevic, L. Wang, J. Wei, and K. Zeno, BNL, USA
}

\section{Abstract}

Beam induced pressure rise in RHIC warm sections is one of the machine luminosity limits. The RHIC electron cloud and the beam transition pressure rise are discussed. Countermeasures and studies for RHIC pressure rise and RHIC upgrade are reported.

\section{INTRODUCTION}

Over several years of operation, the RHIC vacuum situation has been improved. An example is shown in Fig.1. For the same bunch spacing and comparable bunch intensities, in 2002, injection of $\sim 30$ bunches induced $6 \mathrm{e}-7$ Torr pressure rise in 3 single beam straight sections, and in 2005, with injection of 110 bunches, the pressure rises were 2e-9 Torr at same locations. Baking, NEG coating, beam conditioning, and solenoids have contributed to the improvement [1].
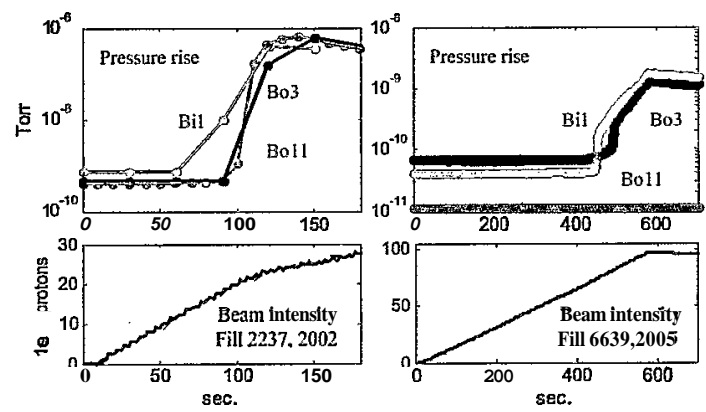

Fig.1. For Fill 2237 in 2002, -30 bunches injected in 110-bunch mode, pressure rose to $6 \mathrm{e}-7$ Torr. For Fill 6639 in 2005, 110 bunches with comparable bunch intensity injected. There was no pressure rise at Boll, where NEG pipes are installed, and $\mathrm{Bil}$ and $\mathrm{Bo} 3$ reached only 2e-9 Torr, due to baking and beam conditioning.

The beam intensity limit due to pressure rise at RHIC, nevertheless, is mainly at interaction regions, where the improvement is more difficult. Therefore, the beam induced pressure rise remains a limit for high intensity heavy ion and proton operations $[2,3]$.

Electron cloud is the main cause for most operationlimit related pressure rise at RHIC. In RHIC beam operations, bunch patterns (hence bunch spacing) have been adjusted to maximize the luminosity while keeping the pressure rise acceptable [4]. Among other countermeasures, the NEG coating has the most effect on the electron cloud threshold and on ion desorption.

*Work performed under Contract No. DE-AC02-98CH1-886 with the auspices of the US Department of Energy
RHIC warm section electron cloud occurs for long bunch spacings, and shows a non-uniform distribution in the ring. Discussion of the mechanism leads to a study of a new countermeasure, which is the anti-grazing ridges installed in straight section beam pipes to reduce haloinduced desorption and secondary electron emission.

Electron multipacting has been detected at the beam transition pressure rise, in beam study with 110 bunch mode and high bunch intensities. Different slope of transition pressure rise versus total beam intensity has been observed for d-Au, $\mathrm{Au}-\mathrm{Au}$, and $\mathrm{Cu}-\mathrm{Cu}$ runs. The possible mechanism is discussed.

The pressure rise limit of the $2005 \mathrm{Cu}-\mathrm{Cu}$ run was not as serious as for $\mathrm{Au}-\mathrm{Au}$ and d-Au runs and is discussed.

For RHIC upgrade, two main studies are underway. One is the electron cloud in cold (cryogenic) regions. Another one is the transition beam instability related to the electron cloud. Plans and some results are reported.

\section{COUNTERMEASURESTO ELECTRON CLOUD}

Given the electron cloud related machine limit, the bunch pattern in RHIC has been routinely adjusted in operations to maximize the luminosity, according to injector conditions and pressure rise in RHIC. For d-Au run, a 56-bunch mode was used. For Au-Au run, a 45bunch was used. It would be desirable to use even fewer bunches in $\mathrm{Au}-\mathrm{Au}$ runs if the injector could provide higher bunch intensity. This was the case in $\mathrm{Cu}-\mathrm{Cu}$ run, where the injector provided more than $6 \mathrm{e} 9$ copper ions per bunch and a 37-bunch mode was used.

Among countermeasures to raise the threshold of electron cloud, a total $250 \mathrm{~m}$ NEG coated beam pipes have been installed in RHIC, and more is planned. Only a few meters of NEG pipes are installed at interaction regions, due to the complexities there. The NEG pipes were activated by baking at 250 degrees $C$ for 1 hour, onsite analysis indicates that it is sufficient.

The effective ion desorption rate of NEG coated pipe has been measured by dumping of $10 \mathrm{GeV} / \mathrm{u}$ copper ions at the incidence angles of 0.7 to $3.3 \mathrm{mrad}$, the rate is low [1]. Suppression of electron cloud induced pressure rise of NEG coated pipes has been observed at all locations without exception[5].

An electron cloud induced pressure rise at a location with NEG pipes was reported in [3] as a question for the effect of NEG pipes. This pressure rise has been observed at all 6 straight sections with NEG pipes fully $(31 \mathrm{~m})$ and largely $(21 \mathrm{~m})$ installed, in both blue and yellow rings. 
Moreover, striking similarities in pressure rise patterns have been observed at these locations. In Fig.2, electron cloud induced pressure rise at pw3.1, at the end of single beam straight sections close to interaction regions (IR), pw3.2, middle of straights, and pw3.3, other ends, are shown for Bi9, Boll, with $31 \mathrm{~m}$, and Bo7 with $21 \mathrm{~m}$ of NEG pipes. The mechanism is under investigation. (Incidently, all 6 such straight sections are with the,beam toward, not away from IR.)

It is noticed that the pressure rise at pw3.2, middle of the straight sections, that was usually the highest, now became the lowest with NEG pipes.

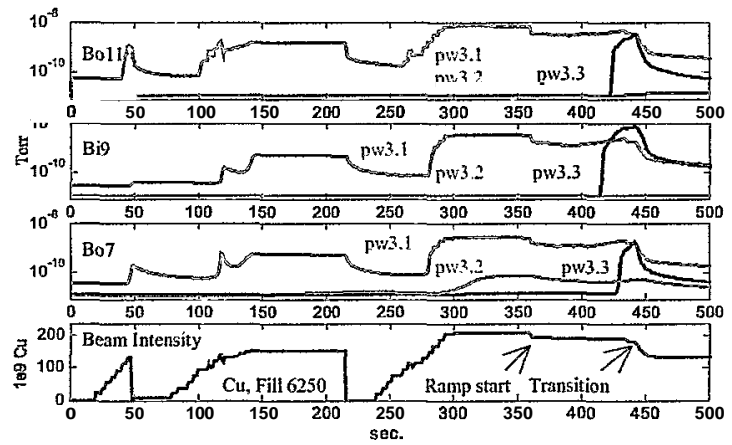

Fig.2. Striking similarities of pressure rise in fully and largely NEG covered single beam straight sections. pw3.1 is at the end of straight sections close to IRs, pw3.3 at the other end, and pw3.2 is in the middle.

\section{WARM SECTION ELECTRON CLOUD}

The' RHIC warm section electron cloud occurs at longer bunch spacing compared with other machines. In Fig.3a, a comparison of electron cloud threshold in terms of bunch intensity versus bunch spacing is shown for SPS RHIC. The SPS case is more representative than the RHIC warm sections for all other machines with electron cloud $[6,7]$, it also agrees with the measured secondary electron's lifetime of $170 \mathrm{~ns}$ at PSR [8].

In Fig.3b, the electron cloud induced pressure rise in 12 single beam straight sections in RHIC yellow ring is shown, the distribution is non-uniform.
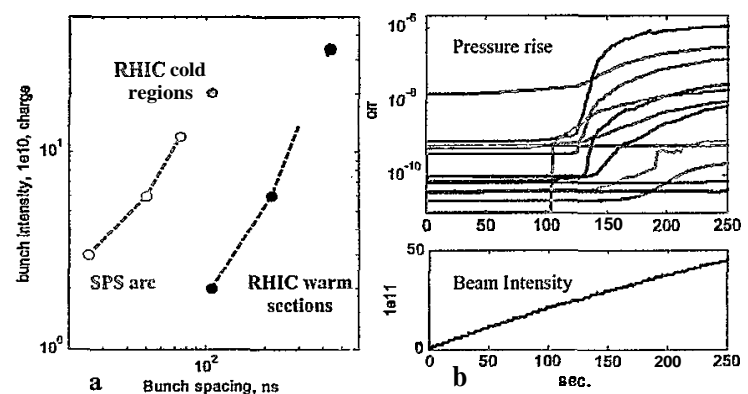

Fig.3a: Electron cloud threshold of bunch intensity vs. bunch spacing for SPS at arc and RHIC warm sections. The magenta dot is for a RHIC beam study, where the pressure rise at cold regions was observed. b: Nonuniform distribution of pressure rise in 12 single-beam straight sections of the yellow ring, for Fill 3667,2003.
In addition to variations of surface and geometry properties, a possible mechanism is that positive ions exist and help to extend the lifetime of the electrons in bunch gaps. These ions may come from beam-gas ionization and/or beam halo scraping. If the beam-gas ionization is dominant, one would expect a correlation between the electron cloud threshold and the static pressure, but it is not always there. For possible beam halo scraping, anti-grazing ridges were proposed and installed in two straight sections to study the effect on the threshold of electron cloud [9]. These ridges are designed to prevent shallow angle beam scraping on chamber wall, and hence to limit ion production. The beam study is underway. In Fig.4, the chamber, beam size, and the ridges at Bi5 and Yo5 are illustrated. Study has shown that the machine aperture has been limited at Ridge 1 in Fig.4, so some modification may be needed. Also during the copper run, halo-type scraping has been observed at Ridge 1 at the beam transitions.

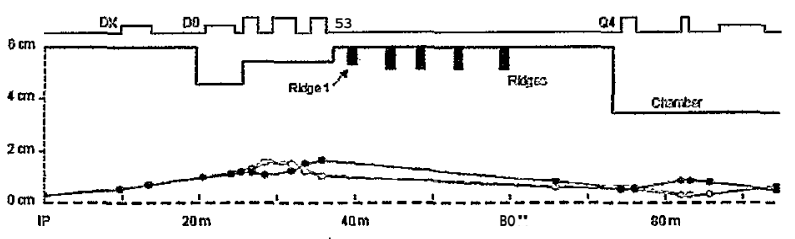

Fig.4. Anti-grazing ridges, chamber and beam sizes, red for horizontal and blue for vertical, are shown. All ridges have a height of $1 \mathrm{~cm}$, except for Ridge 1 which is $0.7 \mathrm{~cm}$.

\section{TRANSITIONPRESSURE RISE}

At the beam transition, shorter bunches with higher peak current can cause the electron multipacting. This was observed in beam studies during the copper run. In Fig.5, the pressure rise and electron signal are shown for the Fill 5919, where 40 bunches in the 110-bunch mode, with $4 \mathrm{e} 9$ copper ions ( $1.16 \mathrm{e} 11$ charges) per bunch, were accelerated passing transition.

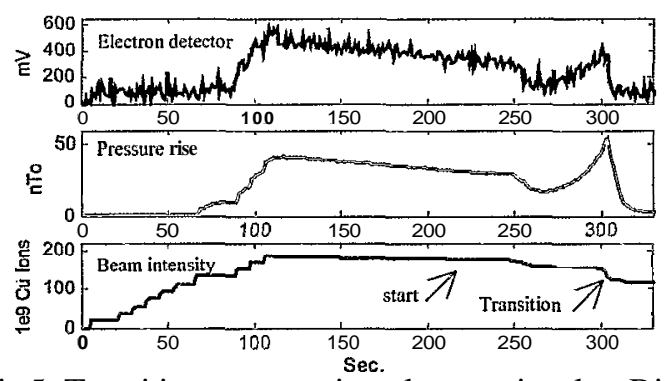

Fig.5. Transition pressure rise, electron signal, at Bil, pw 3.1, and beam intensity of Fill 5919 in $\mathrm{Cu}$ run beam study. 40 bunches in 110-bunchmode with $4 \mathrm{e} 9 \mathrm{Cu}$ ions per bunch were ramped. Electron signal was observed at the transition.

For operations, usually the bunch intensity is lower, and the situation is less clear. With the operations of d-Au 2003, $\mathrm{Au}-\mathrm{Au} 2004$, and $\mathrm{Cu}-\mathrm{Cu} 2005$, the different slopes of transition pressure rise versus total beam intensities have been observed, as shown in Fig.6. 

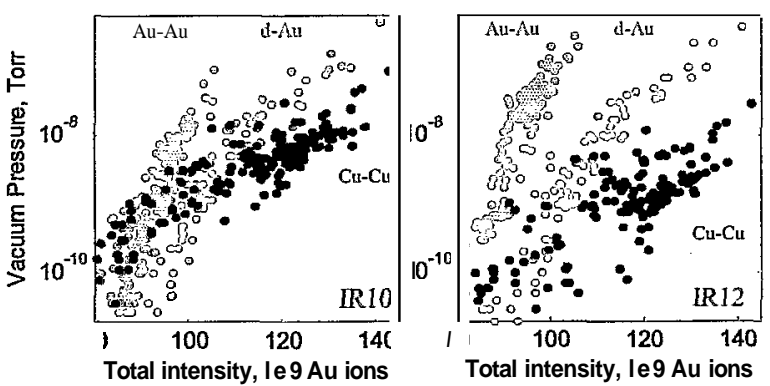

Fig.6. Transition pressure rise at IR10 and IR12 in d-Au run 2003, $\mathrm{Au}-\mathrm{Au}$ run 2004, and $\mathrm{Cu}-\mathrm{Cu}$ run 2005, versus total beam intensity in a charge unit equal to le 9 gold ions. The slope of the pressure rise versus intensity is different for these runs with different species.

The transition pressure rise directly caused the experimental background problem in the d-Au run. In the $\mathrm{Au}-\mathrm{Au}$ nn, the beam rebucketing pressure rise was a main concern. However, at high beam intensity, > 100e9 $\mathrm{Au}$ ions, the transition pressure rise became also relevant. In the $\mathrm{Cu}-\mathrm{Cu}$ run, the pressure rise induced background is not a limit of beam intensity, but the margin is not large.

Note that the typical total intensity was $95 \mathrm{e} 9 \mathrm{Au}$ ions for $\mathrm{Au}-\mathrm{Au}, 110 \mathrm{e} 9 \mathrm{Au}$ ions equivalent for $\mathrm{d}-\mathrm{Au}$, and $125 \mathrm{e} 9$ $\mathrm{Au}$ ions equivalent for $\mathrm{Cu}-\mathrm{Cu}$ nns. At IR10, beams with these intensities are all producing pressure rise of about le-8 Torr.

Among other factors, it is noticed that the pressure rise slope vs. intensity might be related to $\mathbf{Z}$ of the ion species, which is 79 for $\mathrm{Au}-\mathrm{Au}$, average 40 for $\mathrm{d}-\mathrm{Au}$, and 29 for $\mathrm{Cu}-\mathrm{Cu}$. If this effect is confirmed, one would expect that the heavier ions run, such as Uranium, will probably be harder than gold.

\section{COPPER RUN 2005}

For the $2005 \mathrm{Cu}-\mathrm{Cu}$ run, 28 bunch mode was initially proposed. It was based on the following considerations. 1. The injector can provide $6 \mathrm{e} 9 \mathrm{Cu}$ ions per bunch, which is more than 2e9 Au ions charge equivalent. 2. Rebucketing pressure rise causing experimental background would be the most serious concern. Since this is caused by electron cloud, larger bunch spacing would help to raise the threshold. In addition, the total beam intensity at constant luminosity is less for fewer bunches.

Since the mechanism of the beam-gas induced experimental singles, i.e. background, is not well understood, acceptable pressure rise at IRs for the copper run could only be estimated once the operation started. It was found that the beam-gas induced background is about $1 / 3$ of that in $\mathrm{Au}-\mathrm{Au}$ run, given the same pressure rise. Moreover, the beam-beam collision created singles in the Cu-Cu run, according to single Coulomb dissociation, are also about $1 / 3$ of that in the $\mathrm{Au}-\mathrm{Au}$ run. The tolerable pressure rise at IR for the copper $n \mathrm{n}$, therefore, is higher than that for the gold nun. This is illustrated in Fig.7. The operation, hence, used 37-bunch to 42-bunch modes. The experience in the $\mathrm{Cu}-\mathrm{Cu}$ run also reminds us that the pressure rise limit for gold runs remains, unless significant improvements are made.
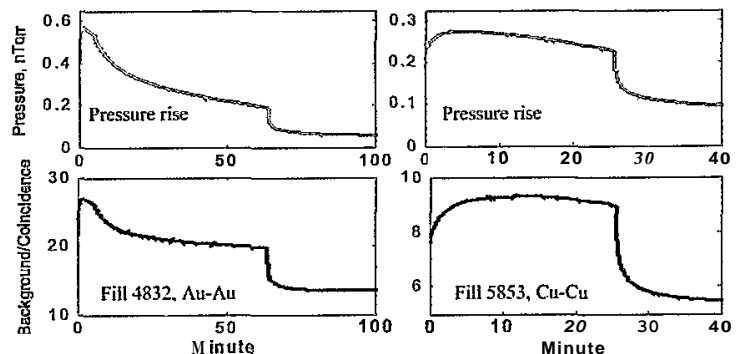

Fig.7. Comparison of pressure rise and the background /coincidence ratio at PHOBOS. The beam-gas created background can be clearly identified. Acceptable pressure rise of the $\mathrm{Cu}-\mathrm{Cu}$ run is higher than for the $\mathrm{Au}$ Au run.

\section{STUDIES FOR RHIC UPGRADE}

The RHIC upgrade plan calls for both gold ion and proton operations with 110 or more bunches, with gold bunch intensity of le9 or higher, and proton bunch intensity of 2e11. The current beam studies toward this goal are mainly the pressure rise at cold regions, and the beam instability at transition.

Beam induced gas density increase at some cryogenic sections has been observed in proton beam studies of Fill 3812, in 2003, and Fill 5350, in 2004. Both had 110 bunches with $2 \mathrm{e} 11$ protons per bunch injected. In terms of electron cloud threshold, this beam is a little below the electron cloud threshold of SPS, but clearly different from the RHIC warm section electron cloud (see Fig. 3a). For further study, two locations were pre-pumped before cooldown to le-3 Torr to reduce the monolayers to 1 or less, also faster logging of temperature and vacuum gauge readings are made available.

With 110-bunch and high bunch intensities, strong electron multipacting is expected at the beam transition for heavy ion operations. Combined with other mechanism, passing transition will be more difficult. In beam studies, about 40 bunches with $5 \mathrm{e} 9 \mathrm{Cu}$ ions per bunch were accelerated. Octupoles and RF voltages were adjusted, but beam loss was always present. Beam transverse motion above the transition was observed at the bunch tails, indicating possible electron cloud induced single bunch instability [10].

\section{REFERENCES}

[1] H.C. Hseuh et al, these proceedings.

[2] W. Fischer et al, ECLOUD'04, California, 2004.

[3] S.Y. Zhang et al, EPAC04, Switzerland, 2004.

[4] W. Fischer and U. Iriso, EPAC04, Switzerland, 2004.

[5] $\mathrm{H}$. Huang et al, these proceedings.

[6] G. Arduini, Chamonix XIII, 2004.

[7] F. Zimmermann, ECLOUD'04, California, 2004.

[8] R. Macek, Two-Stream Instabilities, KEK, 2001

[9] P. Thieberger et al, PRST-AB, Vol.7, 093201, 2004.

[10] J. Wei et al, these proceedings. 